Safety Commission

\title{
ATTENUATION CURVES IN CONCRETE OF NEUTRONS FROM 1 GEV/U C AND U IONS ON A FE TARGET FOR THE SHIELDING DESIGN OF RIB IN-FLIGHT FACILITIES
}

\author{
S. Agosteo ${ }^{(1)}$, G. Fehrenbacher ${ }^{(2)}$ and M. Silari ${ }^{(3)}$ \\ (1) Politecnico di Milano, CESNEF, Via Ponzio 34/3, 20133 Milano, Italy \\ ${ }^{(2)}$ GSI, Planckstrasse 1, 64291 Darmstadt, Germany \\ ${ }^{(3)}$ CERN, 1211 Geneva 23, Switzerland
}

\begin{abstract}
Experimental data on neutron emission from the interaction of heavy ion beams with matter are far less abundant than data on neutron production from protons. The aim of the present work is to extend the computational shielding data to high-energy neutrons produced by heavy ion beams (uranium and carbon) of $1 \mathrm{GeV} / \mathrm{u}$ slowed down in a thick iron target. Source terms and attenuation lengths for neutron attenuation in a concrete shield were calculated starting from experimental neutron energy distributions measured at GSI in the angular range from $0^{\circ}$ to $90^{\circ}$. A comparison is also made with previous calculations performed for different ions and energies and with earlier estimates made at GSI for neon beams with 0.8 and $2 \mathrm{GeV} / \mathrm{u}$ energy stopped in thick iron, lead and uranium targets.
\end{abstract}

Submitted for publication to Nuclear Instruments and Methods B

CERN, 1211 Geneva 23, Switzerland

7 May 2004 


\section{Introduction}

The next generation of Rare Isotope Beam (RIB) facilities is now being planned or is under construction. The two main methods used for the production and separation of rare nuclei are the Isotope Separation On-Line (ISOL) and the In-Flight separation. At ISOL facilities the radioactive nuclei are essentially produced at rest in a thick target, thermalised, ionised and accelerated to energies of 10 to $100 \mathrm{keV}$. After isotope selection by an electromagnetic mass separator they are post-accelerated to Coulomb energies. At In-flight facilities an energetic heavy ion beam $(30 \mathrm{MeV} / \mathrm{u}$ to $1.5 \mathrm{GeV} / \mathrm{u}$ ) is fragmented or fissioned while traversing a thin target. The reaction products are selected for mass, charge and momentum by a fragment separator (Figure 1). An overview of present and planned next generation RIB facilities is given in refs. [1-4].

The beam intensities at these new facilities will increase considerably with respect to the present ones. For example at the new facility at GSI in Darmstadt the primary beam intensities will reach $10^{12}$ uranium ions per second at energy of $1 \mathrm{GeV} / \mathrm{u}$, a factor 100 to 1000 higher compared to the present facility.

This paper discusses shielding data for facilities based on the In-Flight method. The secondary radiation to be attenuated (neutrons and gammas) is generated by the interaction of the primary beam with the nuclei of the target, or during the slowing down and nuclear interactions of both the primary and the fragment beams in the dipole or quadrupole magnets of the fragment separator.

Experimental data on neutron emission from the interaction of heavy ion beams with matter are far less abundant than data on neutron production from protons. Until very recently, the generalised Monte Carlo codes applicable for radiation protection calculations such as FLUKA [5,6], MCNPX [7] and MARS [8], did not generally treat secondary particle production from ions with masses larger than one atomic mass unit. The latest version of FLUKA, just released, includes this feature; ion transport above a few $\mathrm{GeV}$ is well advanced [9] and a model to transport ions down to energy of about $50 \mathrm{MeV}$ per nucleon is presently under implementation. Development work is also under way to implement ion transport in MARS. A heavy ion transport Monte Carlo code HETC-CYRIC [10] and a more generalized code, PHITS, able to treat the fragments produced in heavy ion reactions have recently been developed by Iwase et al. [11,12].

On the other hand, simple line-of-sight models (like the so-called Moyer model [13]) are in many cases useful for a first estimate of shielding requirements. Systematic measurements of yield and energy distribution in the angular range $0^{\circ}-90^{\circ}$ of neutrons produced by the interaction with various targets of ion beams from carbon to xenon with energy of up to $800 \mathrm{MeV} / \mathrm{u}$ were recently published by Kurosawa et al. [14-16]. These spectra were used as input data for Monte Carlo simulations to determine shielding data for concrete for various combinations of target materials and projectiles with energy up to $400 \mathrm{MeV} / \mathrm{u}$ [17].

The aim of this work is to extend the available data to high-energy neutrons produced by heavy ion beams (uranium and carbon) of $1 \mathrm{GeV} / \mathrm{u}$ slowed down in a thick iron target. Hitherto there are no shielding data for neutrons produced by $1 \mathrm{GeV} / \mathrm{u} \mathrm{U}$ ions. The present data are based on measurements - performed at GSI by the time-of-flight method - of neutron spectra in the angular range from $0^{\circ}$ to $90^{\circ}$ relative to the incident beam direction. 


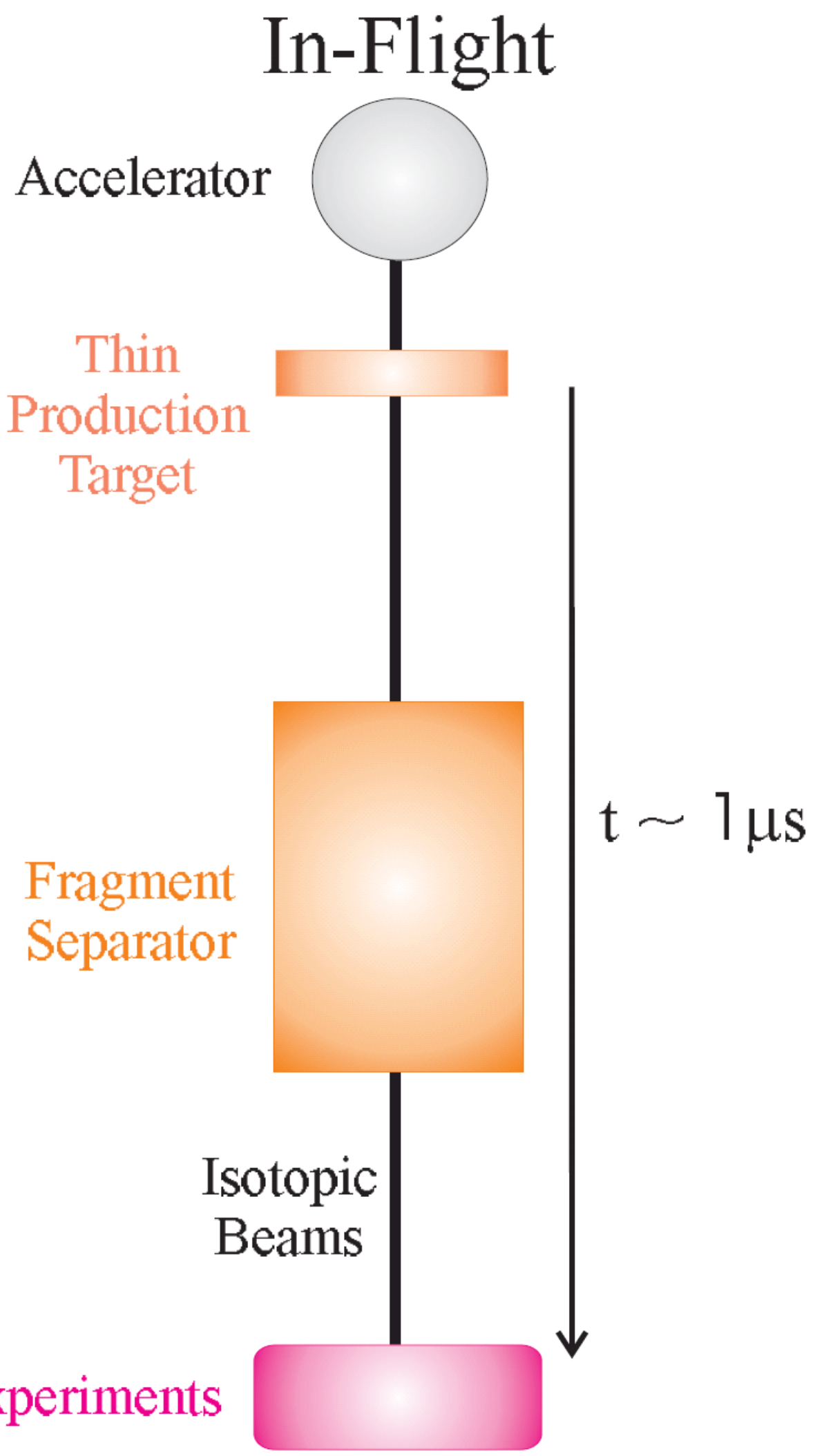

Figure 1. Scheme of the In-flight method for the production of radioactive nuclear beams. The components are the accelerator, the thin production target, the fragment separator and the experiments for the analysis of the isotopes. Nuclides with half lives of 1 usec or longer can be detected with this method. 
The measured neutron spectra served as input for neutron transport calculations performed with the FLUKA code in spherical shielding geometry. The shielding material is concrete. The resulting neutron spectra at various depths in the shield were used to calculate the ambient dose equivalent. In a further step the dose equivalent values were used to determine the parameters of the shielding model, i.e. source terms and attenuation lengths. Finally a comparison is made with previous calculations performed for different ions and energies and with earlier estimates made at GSI for neon beams with 0.8 and $2 \mathrm{GeV} / \mathrm{u}$ energy slowed down in a thick iron, lead and uranium target.

The present data can be used for the estimation of the bulk shielding for Inflight facilities operating with ion beams at $1 \mathrm{GeV} / \mathrm{u}$ for ion masses between carbon and uranium.

\section{Neutron spectra}

The production of secondary neutrons from $1 \mathrm{GeV} / \mathrm{u}{ }^{12} \mathrm{C}$ and ${ }^{238} \mathrm{U}$ ions stopped in a thick iron target $\left(20 \mathrm{~cm}\right.$ thick, $10 \times 10 \mathrm{~cm}^{2}$ cross-sectional area) was recently investigated in experiments performed at the heavy-ion synchrotron SIS-18 at GSI. Fast neutrons were detected by the Large Area Neutron Detector (LAND) positioned about $7 \mathrm{~m}$ downstream of the iron target and in parallel by a smaller $\mathrm{BaF}_{2}$ scintillation detector. The data analysis for LAND is still in progress and the neutron data are not yet available. The neutron spectra shown in Figures 2 and 3 result from a preliminary analysis of the data measured with the $\mathrm{BaF}_{2}$ detector, as discussed in more detail in ref. [18].

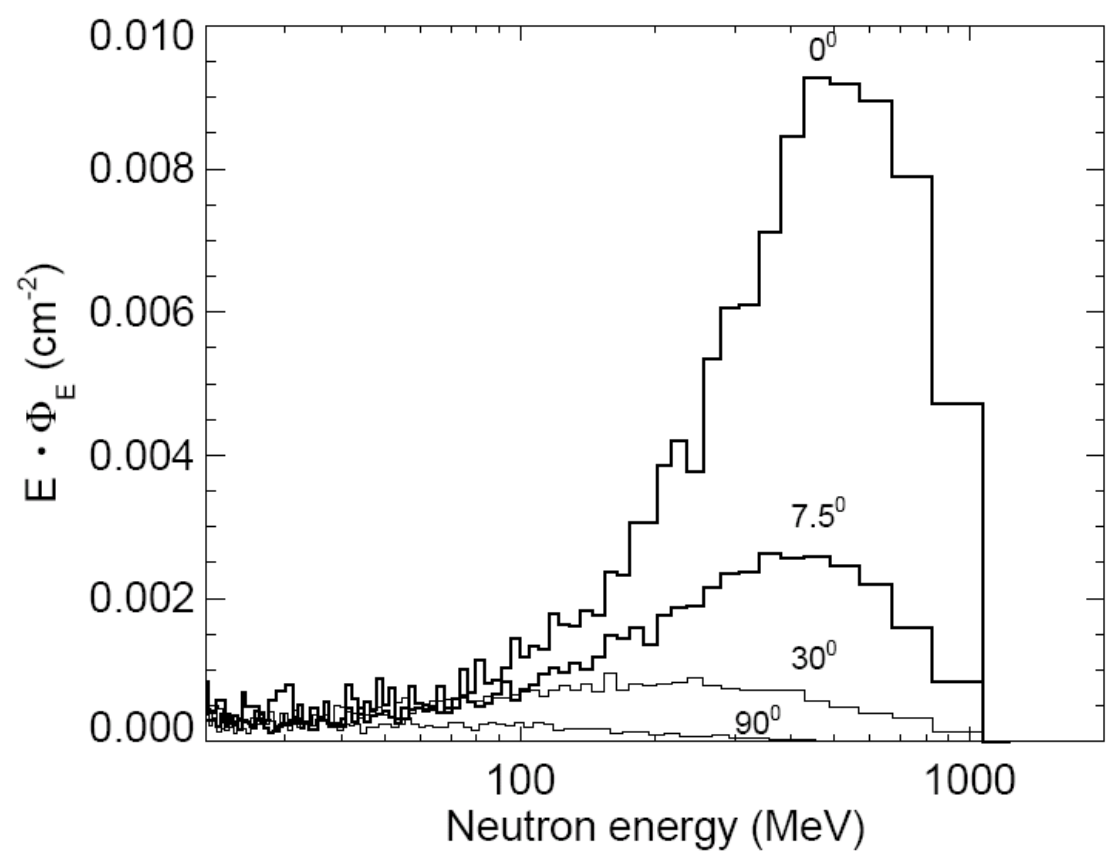

Figure 2. Neutron spectra for an uranium beam at $1 \mathrm{GeV/u}$ stopped in a thick iron target $\left(10 \times 10 \times 20 \mathrm{~cm}^{3}\right)$. The measured spectra are shown for the angles $0^{\circ}, 7.5^{\circ}, 30^{\circ}$ and $90^{\circ}$ (the spectra at $15^{\circ}$ and $50^{\circ}$ are not shown here). The mean neutron energy decreases with the increasing angle. 


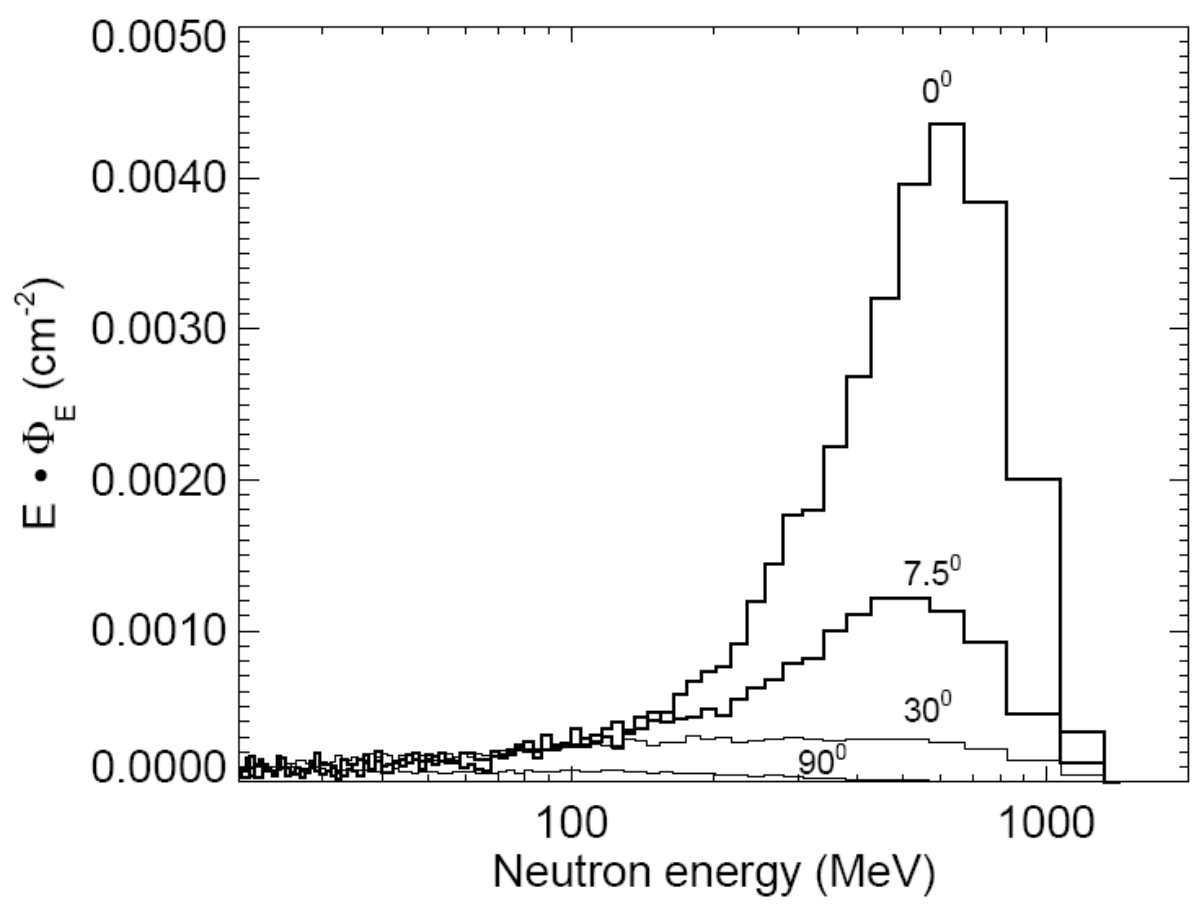

Figure 3. Neutron spectra for a carbon beam at 1 GeV/u. See explanation of fig. 2.

The calculated range of $1 \mathrm{GeV} / \mathrm{u}{ }^{12} \mathrm{C}$ ions in iron is $19.6 \mathrm{~cm}$, i.e. close to the target thickness, while the range of $1 \mathrm{GeV} / \mathrm{u}{ }^{238} \mathrm{U}$ ions is only $1.6 \mathrm{~cm}[19,20]$. Light reaction fragments (mainly neutrons, protons and $\alpha$-particles) emerging from the target were detected by the $\mathrm{BaF}_{2}$ detector at a distance of $5 \mathrm{~m}$ at angles from $0^{\circ}$ to $90^{\circ}$ with respect to the beam direction. The detector consisted of a $14 \mathrm{~cm}$ thick, hexagonally shaped $\mathrm{BaF}_{2}$ scintillator with a neutron efficiency of about $(17 \pm 3) \%$ above $100 \mathrm{MeV}$ [18] and a $9 \mathrm{~mm}$ thick NE102 scintillator in front used as veto detector for the discrimination of charged particles. Neutron energies were obtained from time-of-flight measurements. The start signal was delivered by a $1 \mathrm{~mm}$ thick beam pick-up scintillator placed in front of the target, whilst the stop signal was deduced from the $\mathrm{BaF}_{2}$ detector. The absolute time scale of the time-of-flight measurement was obtained from the position of the prompt gamma-ray peak.

The angular distribution of the neutrons is sharply forward peaked. At small angles a broad maximum can be observed at about half the energy of the primary particles, but the full spectrum extends to energies above the initial energy of the projectile. The fraction of low energy neutrons is growing with increasing angle. The total particle yield emitted from the target was obtained by integrating the energy spectra over the whole forward hemisphere. From the preliminary data analysis the yield of secondary fast neutrons $\left(\mathrm{E}_{\mathrm{n}}>25 \mathrm{MeV}\right)$ was found to be about 20 neutrons per incident ${ }^{12} \mathrm{C}$ ion and 70 neutrons per ${ }^{238} \mathrm{U}$ ion.

\section{Neutron attenuation in concrete}

Source terms and attenuation lengths were calculated by Monte Carlo simulations as in ref. [17]; the procedure is only briefly summarized here. A point neutron source was placed at the centre of a spherical shell, $10 \mathrm{~m}$ thick, made up of concrete TSF-5.5 [21], with inner radius large enough $(90 \mathrm{~m})$ to make effects related 
to curvature negligible. Effects due to neutron scattering are also negligible, since the fluence of neutrons diffusing inside the concrete shell is inversely dependent on its inner surface area [22]. The fluence of outward-directed particles was scored in boundary crossings placed at various depths inside the concrete shell. The effects of the application of this scoring option are discussed in ref. [17]. The concrete shell was also subdivided into polar sectors to account for the angular distribution of the fluence. At projectile energies of $1 \mathrm{GeV} / \mathrm{u}$, a fraction of the energy distribution of the secondary neutrons exceeds the threshold energy for pion production (about $280 \mathrm{MeV}$ [23]) and therefore the fluence of pions generated in concrete was scored in addition to that of neutrons, photons (from neutron absorption and residual nucleus deexcitation) and secondary protons. The ambient dose equivalent was estimated with the conversion coefficients of refs. [24,25]. Geometry splitting and Russian roulette were used as variance reduction techniques for neutron transport inside the concrete shield.

The attenuation curves in concrete at $0^{\circ}-10^{\circ}, 10^{\circ}-20^{\circ}, 40^{\circ}-50^{\circ}$ and $80^{\circ}-90^{\circ}$ for $1 \mathrm{GeV} / \mathrm{u}$ carbon and uranium ions on iron are shown as an example in Figures 4 and 5. The curves at forward angles (up to $50^{\circ}$ ) for both projectiles show a build-up effect, which is not observed at larger angles. At small depths (up to about $60 \mathrm{~cm}$ ), the curve for $1 \mathrm{GeV} / \mathrm{u}$ uranium ions decreases with a slope steeper than at equilibrium. The effect was observed at large angles for ions of lower energies (up to $400 \mathrm{MeV} / \mathrm{u}$ ) [17]. In these cases the lower energy component of the spectrum is attenuated mostly up to a depth of about $100 \mathrm{~cm}$ with a short attenuation length, giving rise to a less intense but harder and thus more penetrating spectral distribution, which is characterised by a larger attenuation length.

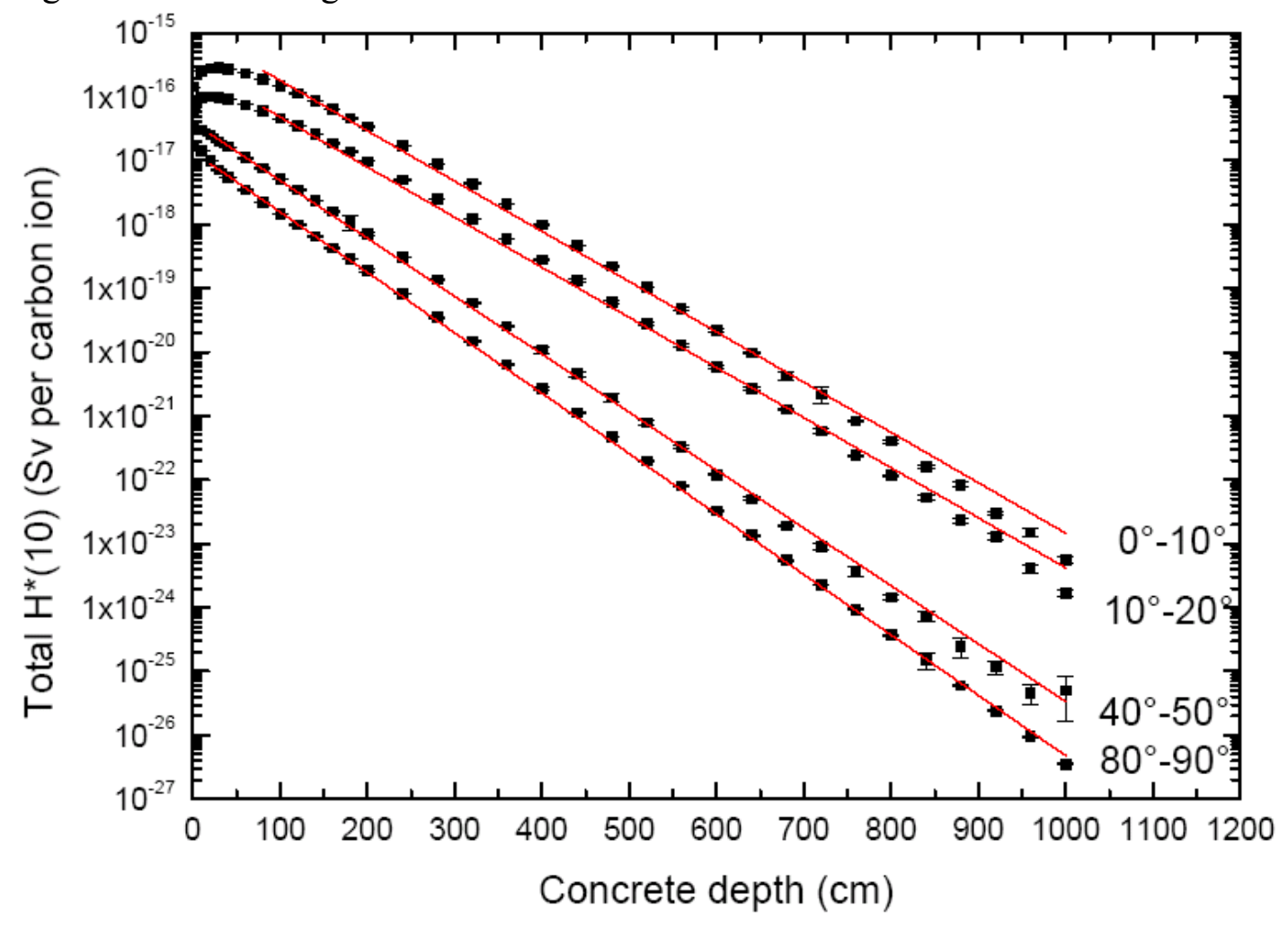

Figure 4. Attenuation curves in concrete at $0^{\circ}-10^{\circ}, 10^{\circ}-20^{\circ}, 40^{\circ}-50^{\circ}$ and $80^{\circ}-90^{\circ}$ for $1 \mathrm{GeV} / \mathrm{u}$ carbon ions on iron. The data were fitted by expression (1). The fitting parameters (source terms and attenuation lengths) are given in Table 1. 


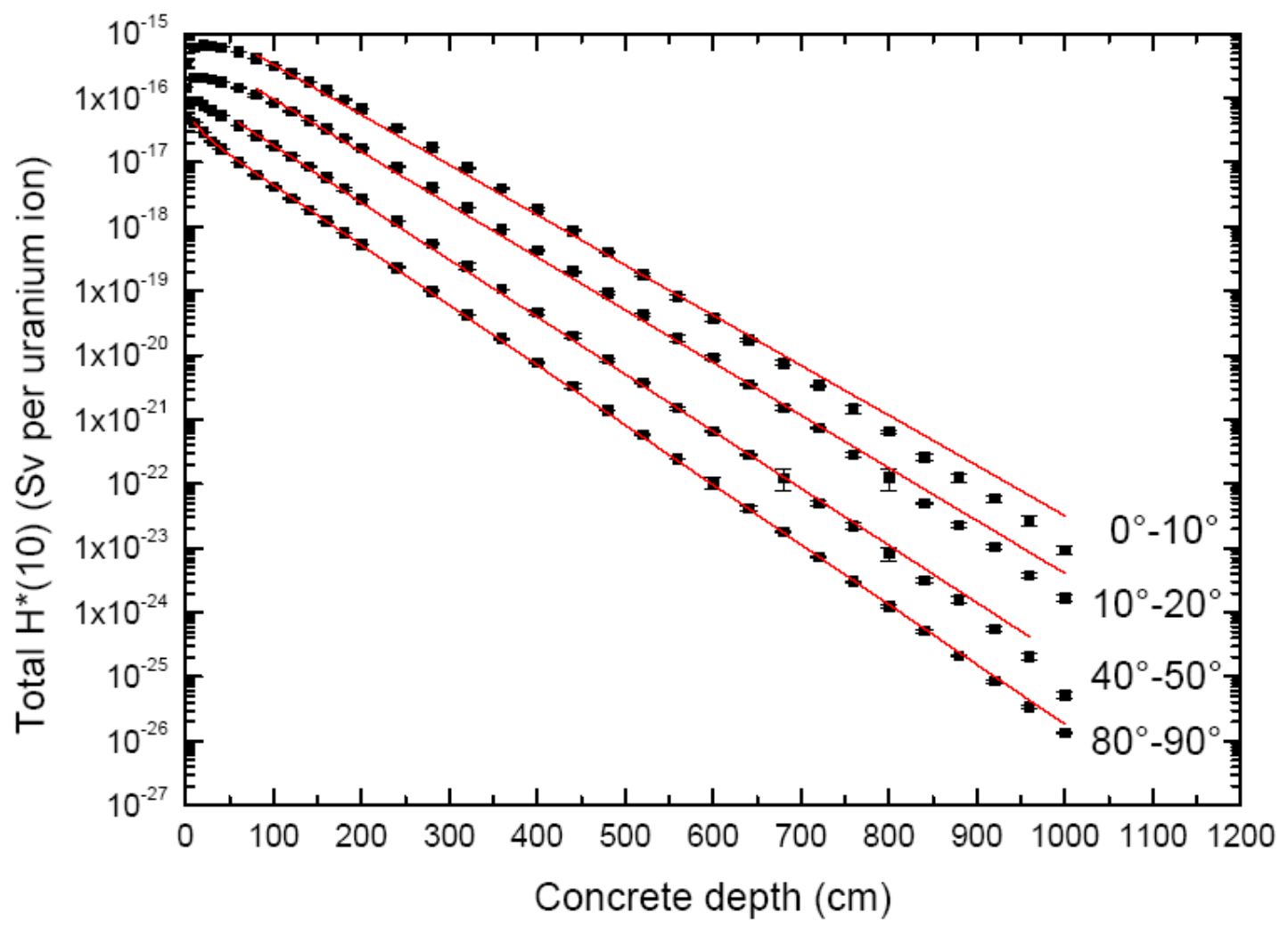

Figure 5. Attenuation curves in concrete at $0^{\circ}-10^{\circ}, 10^{\circ}-20^{\circ}, 40^{\circ}-50^{\circ}$ and $80^{\circ}-90^{\circ}$ for $1 \mathrm{GeV} / \mathrm{u}$ uranium ions on iron. The data were fitted by expression (2). The fitting parameters (source terms and attenuation lengths) are given in Table 2.

The attenuation curves for both projectiles were fitted by the classical twoparameter formula (see, for example, ref. [26]) for all angles except for uranium ions at $80^{\circ}-90^{\circ}$ :

$$
H\left(E_{p}, \theta, d / \lambda\right)=\frac{H_{0}\left(E_{p}, \theta\right)}{r^{2}} \exp \left[-\frac{d}{\lambda_{\theta} g(\alpha)}\right]
$$

where $\mathrm{H}$ is the ambient dose equivalent beyond the shield, $\mathrm{E}_{\mathrm{p}}$ is the energy per nucleon of the projectile, $\mathrm{r}$ is the distance between the radiation source and the scoring position, $\theta$ is the angle between the direction $\vec{r}$ and the beam axis, $\mathrm{H}_{0}$ is the neutron source term, $d$ is the shield thickness, $\lambda_{\theta}$ is the attenuation length and $\alpha$ is the angle between the direction $\vec{r}$ and the normal to the shield surface. The function $g(\alpha)=1$ for the spherical geometry used in the present simulations and $g(\alpha)=\cos \alpha$ in all other cases.

A double-exponential function was used for fitting the attenuation curve of $1 \mathrm{GeV} / \mathrm{u}$ uranium ions on iron at $80-90^{\circ}$ :

$$
H\left(E_{p}, \theta, d / \lambda\right)=\frac{H_{1}\left(E_{p}, \theta\right)}{r^{2}} \exp \left[-\frac{d}{\lambda_{1, \theta} g(\alpha)}\right]+\frac{H_{2}\left(E_{p}, \theta\right)}{r^{2}} \exp \left[-\frac{d}{\lambda_{2, \theta} g(\alpha)}\right]
$$


where $\left(\mathrm{H}_{1}, \lambda_{1, \theta}\right)$ and $\left(\mathrm{H}_{2}, \lambda_{2, \theta}\right)$ are the source terms and the attenuation lengths of the low-depth and large-depth exponential functions, respectively. The second term of expression (2) describes the attenuation beyond $60-100 \mathrm{~cm}$ and obviously cannot be applied at lower depths, because it would lead to an underestimate of the ambient dose equivalent. In practice, expression (2) includes expression (1) by setting $\mathrm{H}_{0}=\mathrm{H}_{2}$, $\lambda_{\theta}=\lambda_{2, \theta}$ and setting the first term to zero (i.e., $H_{1}=\lambda_{1, \theta}=0$ ). The resulting source terms and attenuation lengths are listed in Tables 1 and 2.

Table 1 - Source terms and attenuation lengths in concrete for neutrons generated by $1 \mathrm{GeV} / \mathrm{u} \mathrm{C}$ ions on iron. Data were fitted by expression (1).

\begin{tabular}{|c|c|c|}
\hline Angular bin & $\begin{array}{c}\mathrm{H}_{0} \\
\left(\mathrm{~Sv} \mathrm{~m}^{2} \text { per ion }\right)\end{array}$ & $\begin{array}{c}\lambda \\
\left(\mathrm{g} \mathrm{cm}^{-2}\right)\end{array}$ \\
\hline $0-10^{\circ}$ & $(9.01 \pm 0.04) \times 10^{-12}$ & $128.81 \pm 0.11$ \\
\hline $10-20^{\circ}$ & $(2.39 \pm 0.01) \times 10^{-12}$ & $129.33 \pm 0.13$ \\
\hline $20-30^{\circ}$ & $(1.35 \pm 0.01) \times 10^{-12}$ & $130.58 \pm 0.13$ \\
\hline $30-40^{\circ}$ & $(4.69 \pm 0.02) \times 10^{-13}$ & $121.18 \pm 0.17$ \\
\hline $40-50^{\circ}$ & $(3.21 \pm 0.01) \times 10^{-13}$ & $111.70 \pm 0.13$ \\
\hline $50-60^{\circ}$ & $(2.69 \pm 0.01) \times 10^{-13}$ & $108.15 \pm 0.11$ \\
\hline $60-70^{\circ}$ & $(2.07 \pm 0.01) \times 10^{-13}$ & $109.19 \pm 0.12$ \\
\hline $70-80^{\circ}$ & $(1.56 \pm 0.01) \times 10^{-13}$ & $108.02 \pm 0.08$ \\
\hline $80-90^{\circ}$ & $(1.13 \pm 0.01) \times 10^{-13}$ & $107.03 \pm 0.05$ \\
\hline
\end{tabular}

Table 2 - Source terms and attenuation lengths in concrete for neutrons generated by $1 \mathrm{GeV} / \mathrm{u}$ U ions on iron. Data were fitted by expression (2).

\begin{tabular}{|c|c|c|c|c|}
\hline Angular bin & $\begin{array}{c}\mathrm{H}_{1} \\
\left(\mathrm{~Sv} \mathrm{~m}^{2} \text { per ion }\right)\end{array}$ & $\begin{array}{c}\lambda_{1} \\
\left(\mathrm{~g} \mathrm{~cm}^{-2}\right)\end{array}$ & $\begin{array}{c}\mathrm{H}_{2} \\
\left(\mathrm{~Sv} \mathrm{~m}^{2} \text { per ion }\right)\end{array}$ & $\begin{array}{c}\lambda_{2} \\
\left(\mathrm{~g} \mathrm{~cm}^{-2}\right)\end{array}$ \\
\hline $0-10^{\circ}$ & - & - & $(1.55 \pm 0.01) \times 10^{-11}$ & $137.41 \pm 0.27$ \\
\hline $10-20^{\circ}$ & - & - & $(4.42 \pm 0.04) \times 10^{-12}$ & $130.30 \pm 0.27$ \\
\hline $20-30^{\circ}$ & - & - & $(2.62 \pm 0.02) \times 10^{-12}$ & $128.50 \pm 0.24$ \\
\hline $30-40^{\circ}$ & - & - & $(1.52 \pm 0.01) \times 10^{-12}$ & $121.04 \pm 0.26$ \\
\hline $40-50^{\circ}$ & - & - & $(1.02 \pm 0.01) \times 10^{-12}$ & $119.69 \pm 0.23$ \\
\hline $50-60^{\circ}$ & - & - & $(7.56 \pm 0.03) \times 10^{-13}$ & $114.91 \pm 0.17$ \\
\hline $60-70^{\circ}$ & - & - & $(5.84 \pm 0.04) \times 10^{-13}$ & $114.25 \pm 0.21$ \\
\hline $70-80^{\circ}$ & - & - & $(4.34 \pm 0.02) \times 10^{-13}$ & $112.01 \pm 0.15$ \\
\hline $80-90^{\circ}$ & $(2.95 \pm 0.37) \times 10^{-13}$ & $25.41 \pm 2.09$ & $(2.85 \pm 0.02) \times 10^{-13}$ & $110.48 \pm 0.10$ \\
\hline
\end{tabular}

It should be noted (Figures 6 and 7) that at forward angles (up to $50^{\circ}$ ), the single exponential fit (expression (1)) overestimates the simulation data (up to about a factor of 2) at the largest depths. This is due to a softening of the neutron spectrum at concrete depths larger than about $600 \mathrm{~cm}$. The fitting procedure with a double exponential function (expression (2)) with four free parameters $\left(\mathrm{H}_{1}, \mathrm{H}_{2}, \lambda_{1}, \lambda_{2}\right)$ gave source terms with the same absolute value (within the uncertainties) but with opposite sign (i.e. $\mathrm{H}_{1}=-\mathrm{H}_{2}$ ). The source terms and "attenuation lengths" (formally, $\lambda_{1}^{\prime}$ and $\lambda_{2}^{\prime}$ do not have the physical meaning of an attenuation length) resulting from fitting the data (up to $30^{\circ}$ for carbon and to $50^{\circ}$ for uranium) with a double exponential function with three free parameters $\left(H_{0}^{\prime}, \lambda_{1}^{\prime}, \lambda_{2}^{\prime}\right)$ :

$H\left(E_{p}, \theta, d / \lambda\right)=\frac{H_{0}^{\prime}\left(E_{p}, \theta\right)}{r^{2}}\left\{\exp \left[-\frac{d}{\lambda_{1}^{\prime} g(\alpha)}\right]-\exp \left[-\frac{d}{\lambda_{2}^{\prime} g(\alpha)}\right]\right\}$ 
are listed in Tables 3 and 4. The corresponding fits are shown in Figures 6 and 7. It should be underlined that although expression (3) fits better the data up to $30^{\circ}$ for carbon and to $50^{\circ}$ for uranium, the use of expression (1) leads to a conservative estimate of the ambient dose equivalent.

Table 3 - Source terms and "attenuation lengths" (from $0^{\circ}$ to $30^{\circ}$ ) in concrete for neutrons generated by $1 \mathrm{GeV} / u \mathrm{C}$ ions on iron. Data were fitted by expression (3).

\begin{tabular}{|c|c|c|c|}
\hline Angular bin & $\begin{array}{c}H_{0}^{\prime} \\
\left(\mathrm{Sv} \mathrm{m}^{2} \text { per ion }\right)\end{array}$ & $\begin{array}{c}\lambda_{1}^{\prime} \\
\left(\mathrm{g} \mathrm{cm}^{-2}\right)\end{array}$ & $\begin{array}{c}\lambda_{2}^{\prime} \\
\left(\mathrm{g} \mathrm{cm}^{-2}\right)\end{array}$ \\
\hline $0-10^{\circ}$ & $(2.64 \pm 0.13) \times 10^{-11}$ & $117.53 \pm 0.41$ & $96.78 \pm 0.73$ \\
\hline $10-20^{\circ}$ & $(5.22 \pm 0.17) \times 10^{-12}$ & $120.59 \pm 0.34$ & $88.47 \pm 0.81$ \\
\hline $20-30^{\circ}$ & $(2.06 \pm 0.03) \times 10^{-12}$ & $124.82 \pm 0.23$ & $72.43 \pm 0.60$ \\
\hline
\end{tabular}

Table 4 - Source terms and "attenuation lengths" (from $0^{\circ}$ to $30^{\circ}$ ) in concrete for neutrons generated by $1 \mathrm{GeV} / \mathrm{u} \mathrm{U}$ ions on iron. Data were fitted by expression (3).

\begin{tabular}{|c|c|c|c|}
\hline Angular bin & $\begin{array}{c}H_{0}^{\prime} \\
\left(\mathrm{Sv} \mathrm{m}^{2} \text { per ion }\right)\end{array}$ & $\begin{array}{c}\lambda_{1}^{\prime} \\
\left(\mathrm{g} \mathrm{cm}^{-2}\right)\end{array}$ & $\begin{array}{c}\lambda_{2}^{\prime} \\
\left(\mathrm{g} \mathrm{cm}^{-2}\right)\end{array}$ \\
\hline $0-10^{\circ}$ & $(4.66 \pm 0.23) \times 10^{-11}$ & $117.50 \pm 0.46$ & $92.86 \pm 0.82$ \\
\hline $10-20^{\circ}$ & $(1.07 \pm 0.04) \times 10^{-11}$ & $116.05 \pm 0.34$ & $87.17 \pm 0.72$ \\
\hline $20-30^{\circ}$ & $(7.06 \pm 0.40) \times 10^{-12}$ & $113.77 \pm 0.46$ & $89.31 \pm 1.08$ \\
\hline $30-40^{\circ}$ & $(2.64 \pm 0.06) \times 10^{-12}$ & $110.10 \pm 0.31$ & $70.20 \pm 0.92$ \\
\hline $40-50^{\circ}$ & $(1.10 \pm 0.01) \times 10^{-12}$ & $114.54 \pm 0.13$ & $24.64 \pm 0.52$ \\
\hline
\end{tabular}

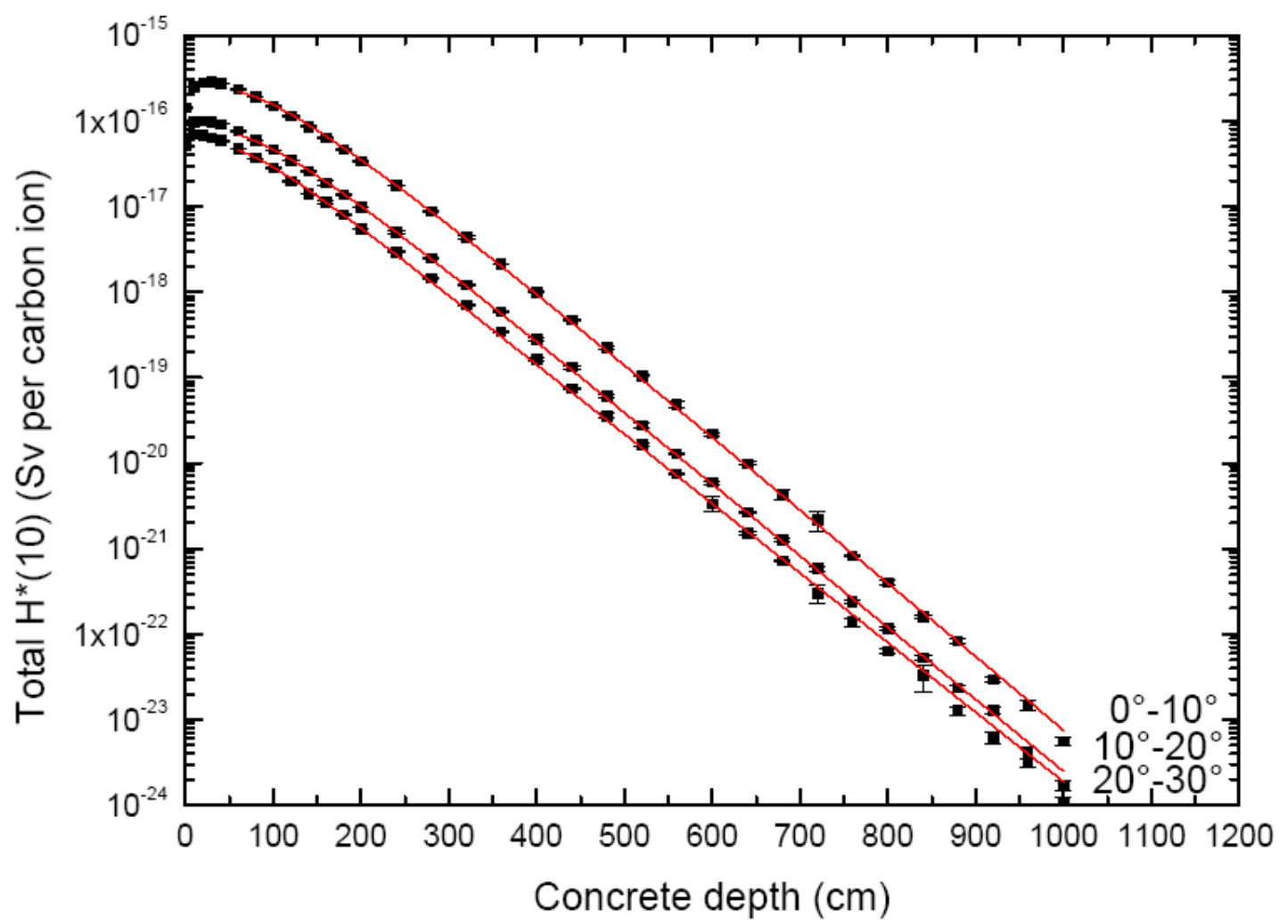

Figure 6. Attenuation curves in concrete at $0^{\circ}-10^{\circ}, 10^{\circ}-20^{\circ}$ and $20^{\circ}-30^{\circ}$ for $1 \mathrm{GeV} / \mathrm{u}$ carbon ions on iron. The data were fitted by expression (3). The fitting parameters (source terms and attenuation lengths) are given in Table 3. 


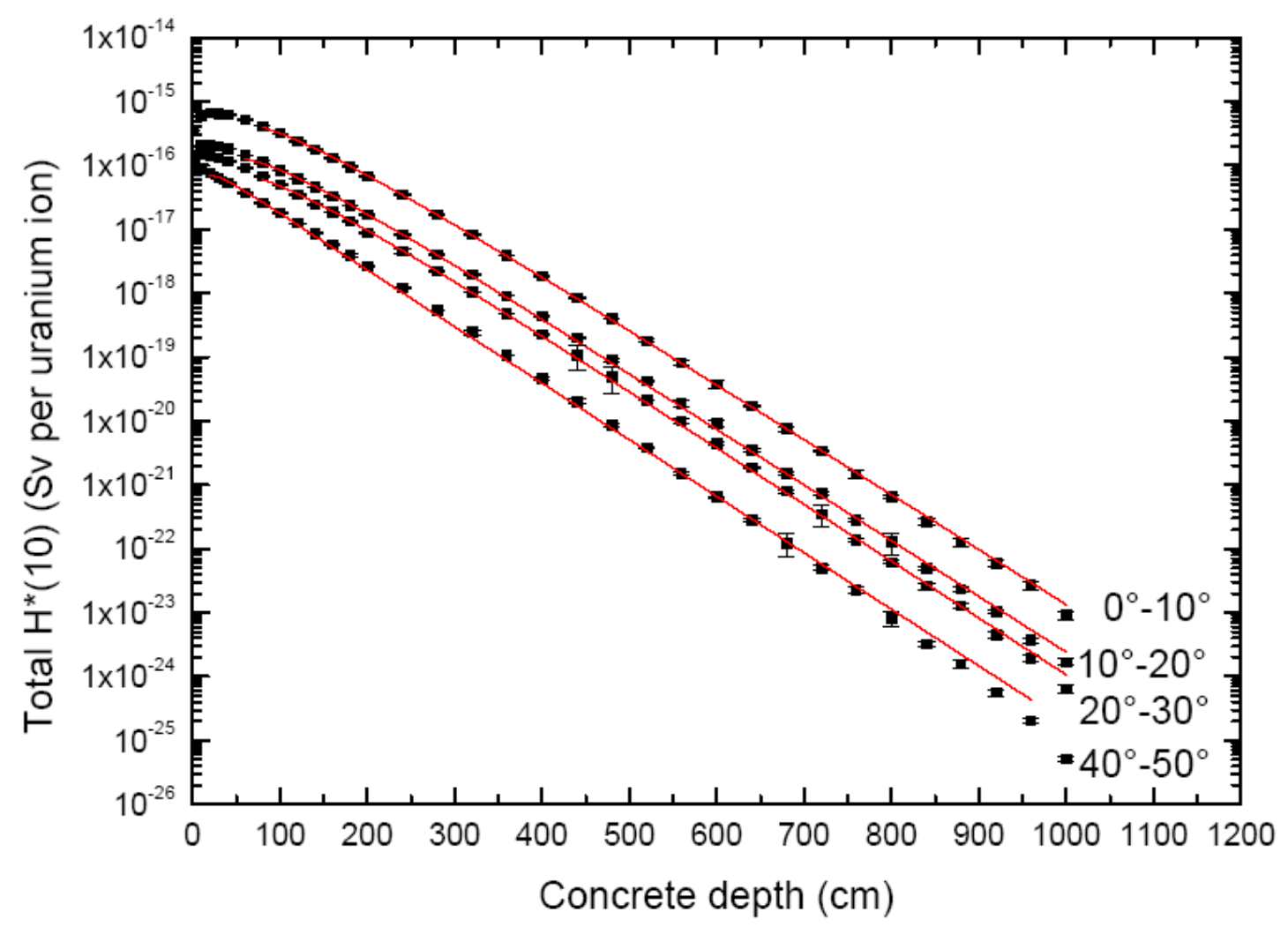

Figure 7. Attenuation curves in concrete at $0^{\circ}-10^{\circ}, 10^{\circ}-20^{\circ}, 20^{\circ}-30^{\circ}$ and $40^{\circ}-50^{\circ}$ for $1 \mathrm{GeV} / \mathrm{u}$ uranium ions on iron. The data were fitted by expression (3). The fitting parameters (source terms and attenuation lengths) are given in Table 4.

\section{Discussion}

\subsection{Comparison with previous calculations for different ions and energies}

The attenuation lengths in ordinary concrete for forward $\left(0^{\circ}-10^{\circ}\right)$, intermediate $\left(40^{\circ}-50^{\circ}\right)$ and transverse $\left(80^{\circ}-90^{\circ}\right)$ neutron emission are compared in Figure 8 to the data recently calculated for 100 and $400 \mathrm{MeV} / \mathrm{u}$ ions [17]. The data in Figure 8 are the mean values of the attenuation lengths for the various projectile-target combinations from ref. [17] and from the present work. The attenuation lengths increase with the energy per nucleon of the projectile up to about $400 \mathrm{MeV} / \mathrm{u}$. At higher energies the inelastic cross section for neutron interactions with concrete tends to its geometrical value, thus explaining the flattening of the curves. For the other angles, the data lie inbetween those for the forward and transverse directions. The mean attenuation lengths for all angles and ion energies are listed in Table 5. For the transverse direction, the almost-asymptotic value of $108 \mathrm{~g} \mathrm{~cm}^{-2}$ is in good agreement with the high-energy value of $\lambda$ for ordinary concrete for proton accelerator shielding (usually taken around $120 \mathrm{~g} \mathrm{~cm}^{-2}$ above a few $\mathrm{GeV}$, see for example ref. [26]).

The attenuation lengths for ions in the energy interval 30-100 MeV/u can be calculated with a simple model in use at GANIL, based on experimental data of the differential yield of secondary neutrons. For $100 \mathrm{MeV} / \mathrm{u}$ ions, the attenuation lengths calculated with the GANIL model were compared to those computed by Monte Carlo [17], showing a satisfactory agreement. 


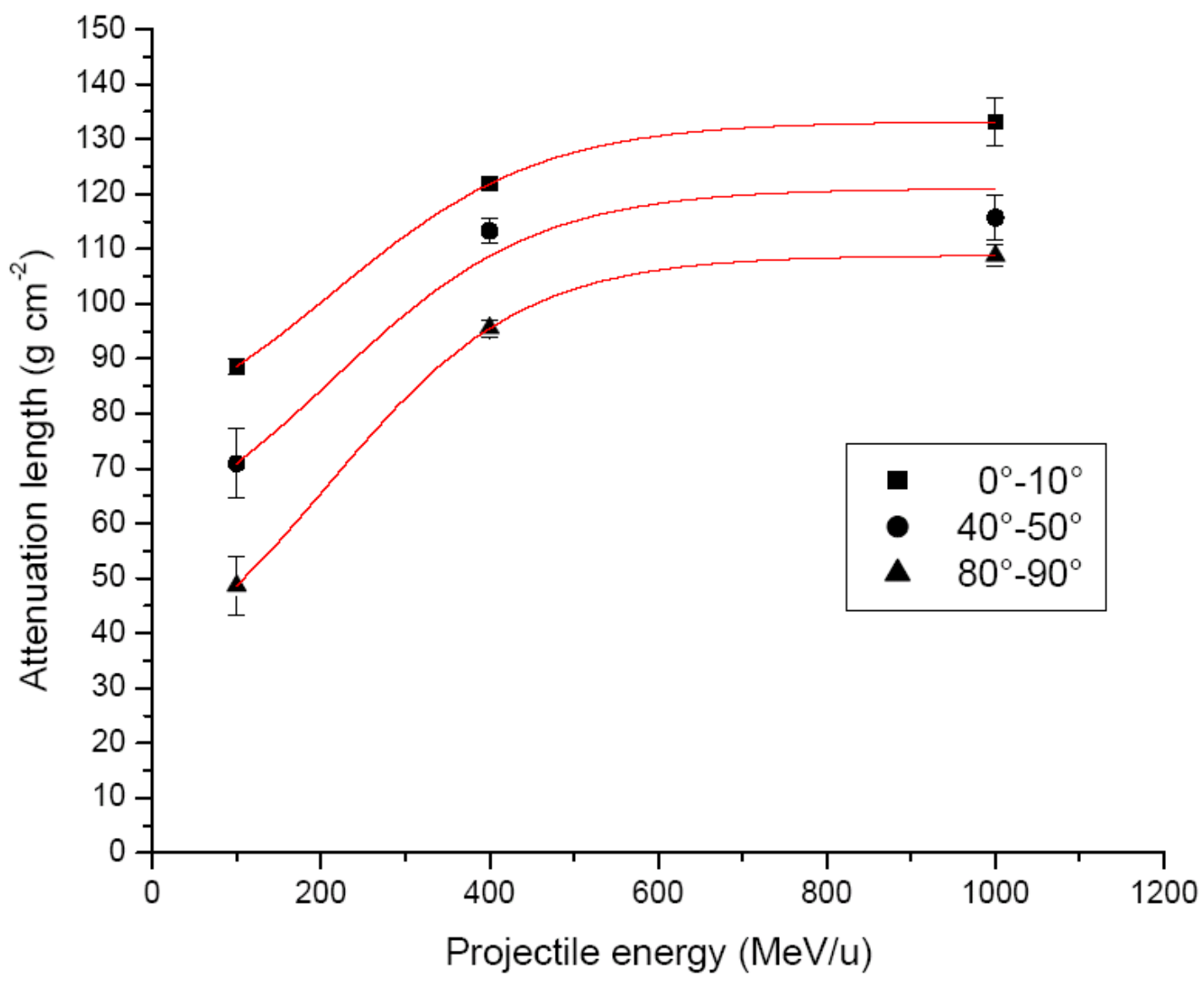

Figure 8. Attenuation lengths in ordinary concrete for secondary neutrons generated at $0^{\circ}-10^{\circ}, 40^{\circ}-50^{\circ}$ and $80^{\circ}-90^{\circ}$ by 100,400 and $1000 \mathrm{MeV} / \mathrm{u}$ ions. The solid lines are only to guide the eye.

Table 5 - Attenuation lengths averaged over various ion-target combinations for different energy per nucleon of the projectile. Data for $100 \mathrm{MeV} / \mathrm{u}$ and $400 \mathrm{MeV} / \mathrm{u}$ are from ref. [17].

\begin{tabular}{|c|c|c|c|}
\hline & \multicolumn{3}{|c|}{ Ion energy } \\
\hline Angular bin & $100 \mathrm{MeV} / \mathrm{u}$ & $400 \mathrm{MeV} / \mathrm{u}$ & $1000 \mathrm{MeV} / \mathrm{u}$ \\
\hline $0-10^{\circ}$ & $88.55 \pm 1.37$ & $121.90 \pm 0.31$ & $133.11 \pm 4.30$ \\
\hline $10-20^{\circ}$ & $87.57 \pm 1.60$ & $122.74 \pm 0.70$ & $129.81 \pm 0.48$ \\
\hline $20-30^{\circ}$ & $82.02 \pm 3.51$ & $122.24 \pm 1.06$ & $129.58 \pm 1.00$ \\
\hline $30-40^{\circ}$ & $77.09 \pm 4.47$ & $118.40 \pm 1.18$ & $121.11 \pm 0.07$ \\
\hline $40-50^{\circ}$ & $70.94 \pm 6.38$ & $113.31 \pm 2.34$ & $115.69 \pm 4.00$ \\
\hline $50-60^{\circ}$ & $67.62 \pm 6.16$ & $108.59 \pm 2.72$ & $111.53 \pm 3.38$ \\
\hline $60-70^{\circ}$ & $61.82 \pm 5.83$ & $102.59 \pm 1.95$ & $111.72 \pm 2.53$ \\
\hline $70-80^{\circ}$ & $51.14 \pm 5.25$ & $97.10 \pm 1.56$ & $110.01 \pm 2.00$ \\
\hline $80-90^{\circ}$ & $48.67 \pm 5.64$ & $95.59 \pm 2.54$ & $108.75 \pm 1.73$ \\
\hline
\end{tabular}

\subsection{Comparison with previous calculations at GSI}

For the shielding design of the heavy ion synchrotron (SIS18) at GSI various models were employed, starting from the neutron production by neon beams with 0.8 , 2 and $2.1 \mathrm{GeV} / \mathrm{u}$ stopped in thick iron, lead or uranium targets [27]. The neutron production from $2 \mathrm{GeV} / \mathrm{u}$ neon ions was estimated by Monte Carlo calculations as a function of the angle relative to the incident beam [28,29]. Alternatively to these 
calculations the neutron distribution was derived from cross section data from relativistic heavy ion collisions [30]. Source neutrons with energies lower than $100 \mathrm{MeV}$ were generally neglected. The shielding effect of concrete was represented by one exponential function. The dose equivalent per ion at $1 \mathrm{~m}$ distance was derived from the angle-specific neutron source strength, an average dose conversion factor and a build-up factor for neutron radiation in concrete. These quantities are summarized in the parameter $\mathrm{H}_{0}\left(\mathrm{~Sv} \mathrm{~m}^{2}\right)$ according to the model discussed above. The results for $\mathrm{H}_{0}$ are shown in Figure 9 together with the values of $\mathrm{H}_{2}$ for $1 \mathrm{GeV} / \mathrm{u}$ uranium ions (Table 2 and Figure 5). In the forward direction the $\mathrm{Ne}$ beams at $2 \mathrm{GeV} / \mathrm{u}$ show $\mathrm{H}_{0}$ values about one order of magnitude higher than the corresponding figures for $1 \mathrm{GeV} / \mathrm{u}$ uranium. At $0^{\circ}$ the $0.8 \mathrm{GeV} / \mathrm{u}$ Ne beam shows a $\mathrm{H}_{0}$ value close to the one for uranium. At larger angles the uranium beam show comparatively higher values as compared with the Ne beam either at 2 or at $0.8 \mathrm{GeV} / \mathrm{u}$. This might be a consequence of the fission of uranium nuclei which causes a broader angular distribution of the emitted neutrons.

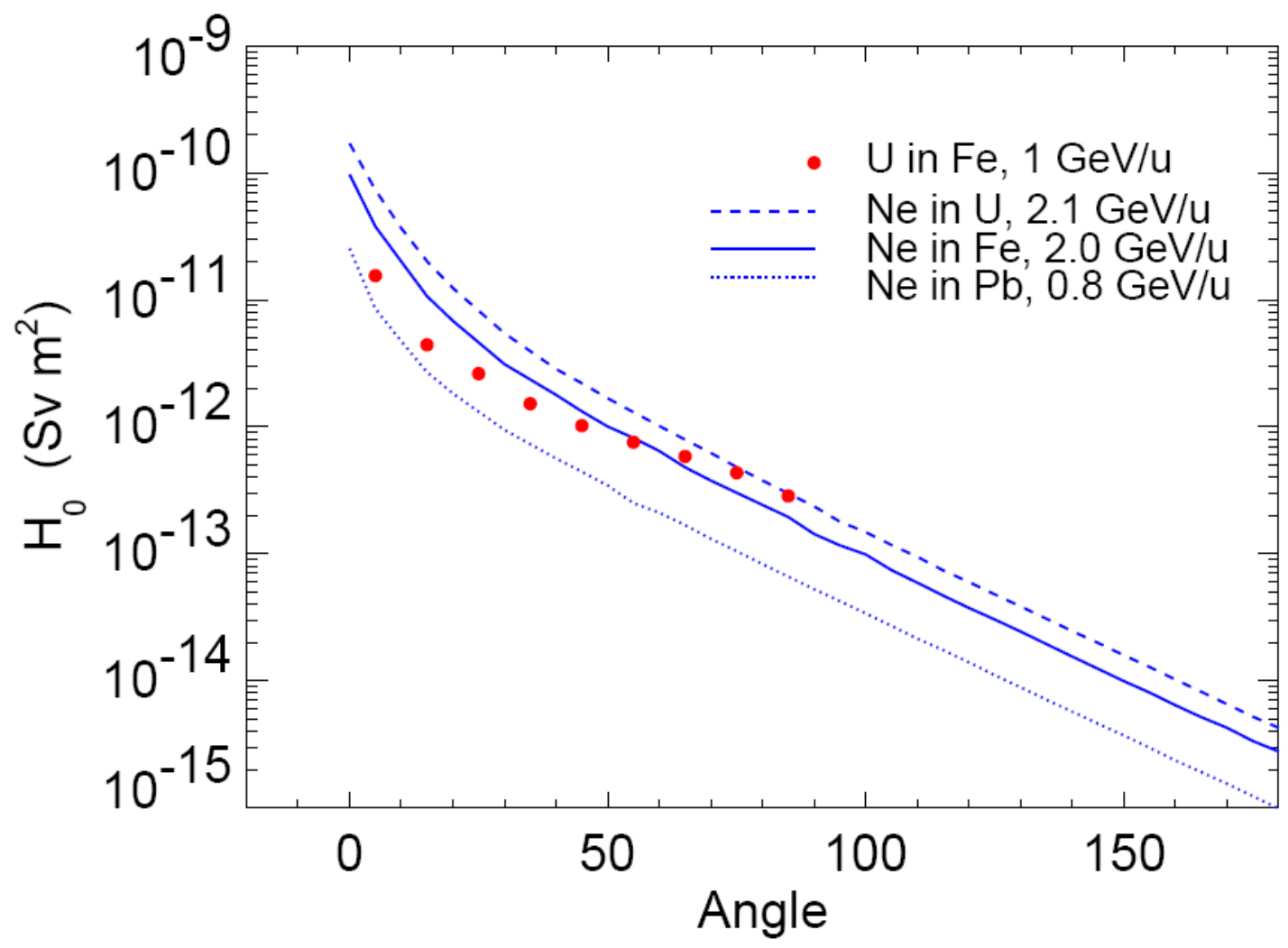

Figure 9. Source strength parameter $H_{0}$ for various ion-target combinations. For comparison other shielding models used at GSI are shown for neon beams at 0.8, 2.0 and $2.1 \mathrm{GeV} / \mathrm{u}$ stopped in thick lead, iron and uranium targets (dotted, solid, dashed line). The corresponding values of the uranium beam at $1 \mathrm{GeV} / \mathrm{u}$ are given as full points from $0^{\circ}$ to $90^{\circ}$.

The attenuation lengths are shown in Figure 10. The neon beams at 2 and $2.1 \mathrm{GeV} / \mathrm{u}$ have the same attenuation function. The neon beam with $0.8 \mathrm{GeV} / \mathrm{u}$ is closer to the values of the uranium beam. The uranium beam shows the lowest values of $\lambda$, indicating that the attenuation of the neutron radiation by the shield is more 
efficient. This might be a consequence of a larger proportion of low energy neutrons in the spectrum.

The attenuation lengths for $1 \mathrm{GeV} / \mathrm{u}$ uranium ions in the angular range $0^{\circ}$ to $90^{\circ}$ compare well with data in Table 5 and in Figure 8. On the other hand the $\lambda$-values for the other ions appear, especially at the forward angles, too high. This discrepancy may be due to the fact that these data were derived from neutron energy distributions generated by interaction of heavy ions in a very massive dump ( $3 \mathrm{~m}$ in length) and then extrapolated to thin target.

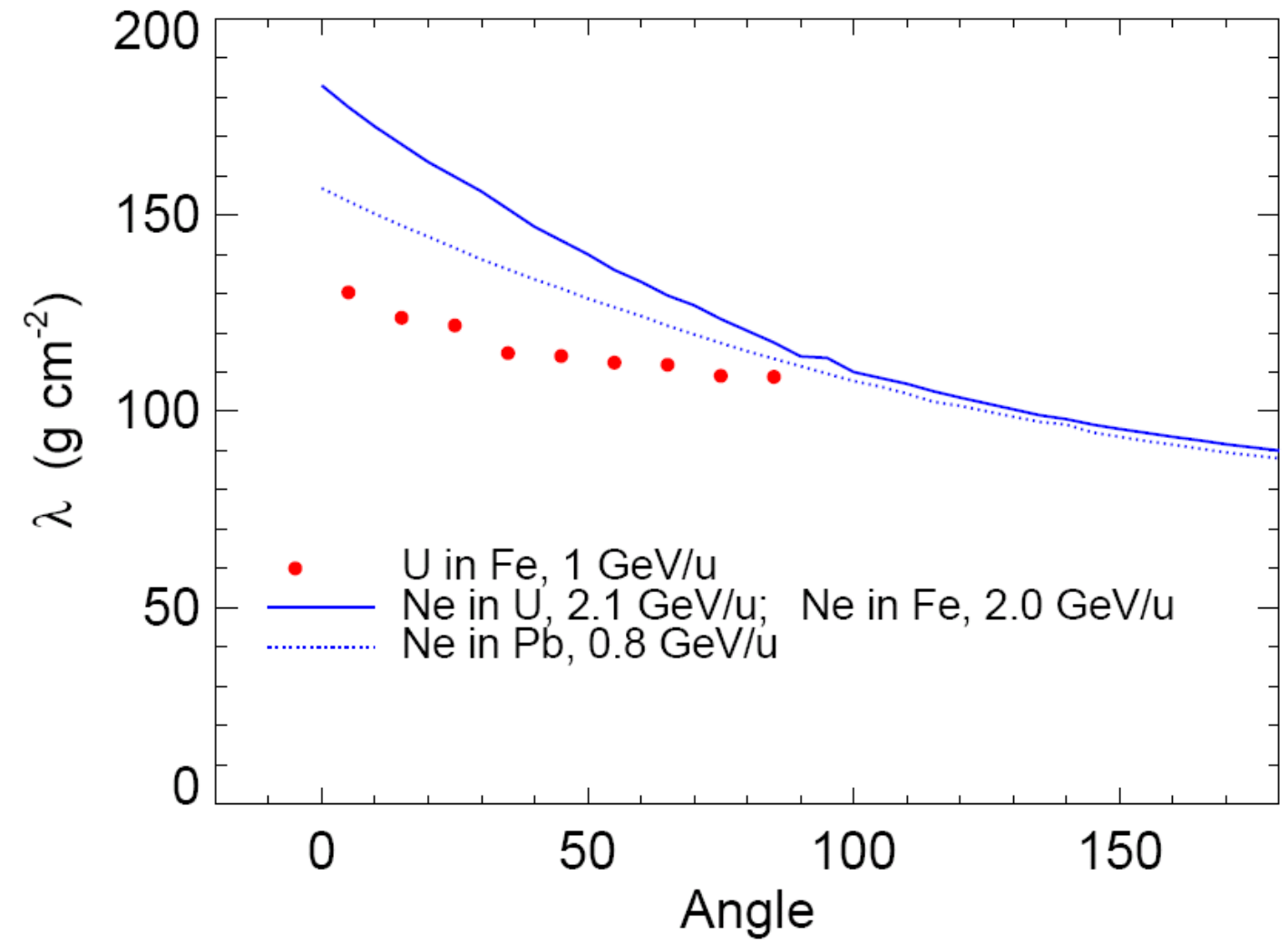

Figure 10. Neutron attenuation parameter for the neon beams (see fig. 4) and the uranium beam. The values for a uranium beam are lower than the corresponding one of the neon beams. This reflects the better absorption of neutrons with lower energies. This can be explained by the higher stopping power of uranium in the target, the lower energy of the ion when it undergoes a nuclear reaction and consequently the higher proportion of low energetic neutrons.

\section{Conclusions}

Experimental data on neutron emission from the interaction of heavy ion beams with matter are rather scarce as compared to the existing literature on neutron production from protons. In addition, until very recently the generalised Monte Carlo codes applicable for radiation protection calculations did not generally treat secondary particle production from ions with masses larger than one atomic mass unit. Simple point- or line-source/line-of-sight models are often useful in a first approach to define shielding requirements. These simple models essentially require the knowledge of two parameters, a source term and an attenuation length. A simple model developed at GANIL for ion energies in the range $30-100 \mathrm{MeV} / \mathrm{u}$ seems to provide a reasonable 
tool for simple estimates, although it shows some important overestimates at large depths in the shield [17].

At ultra-relativistic energies, i.e. hundreds of $\mathrm{GeV} / \mathrm{u}$, the approach of considering an ion of mass A equivalent to a bunch of A protons is a sufficiently good approximation for shielding purposes [31-34]. However, at energies below several $\mathrm{GeV} / \mathrm{u}$ assuming the ion as a bunch of free protons generally leads to an underestimate of the shielding requirement, by a factor that becomes increasingly larger with increasing shielding thickness, especially at forward angles [17]. This is because secondary neutrons generated from ion interaction have a spectrum that extends to a maximum energy which is about twice the projectile energy per nucleon. This penetrating component would dominate the radiation dose past a thick shield.

The design of the next generation of Rare Isotope Beam facilities needs models and data to estimate the attenuation of the radiation produced in the bulk shielding and the dose equivalent rates outside the shielding. The present paper tries to complement the few data available in the energy range between $100 \mathrm{MeV} / \mathrm{u}$ and a few $\mathrm{GeV} / \mathrm{u}$. Shielding data for concrete for various combinations of target materials and projectiles with energy up to $400 \mathrm{MeV} / \mathrm{u}$ were recently calculated from experimental neutron spectral measurements [17]. One of these data was recently confirmed experimentally [35]. In the present work shielding data were derived for $1 \mathrm{GeV} / \mathrm{u}$ carbon and uranium ion beams stopped in a thick iron target. The data are based on neutron spectra measured at GSI by means of the TOF technique [18].

In the past GSI used, for the planning of the heavy ion synchrotron SIS18, shielding data based on a $2 \mathrm{GeV} / \mathrm{u}$ neon beam stopped in a $3 \mathrm{~m}$ thick iron block. The large size of the stopper causes a substantial attenuation of the neutron radiation produced in the forward direction [27, 28, 29]. The derived attenuation lengths are larger than the corresponding ones obtained for comparable ion beams, leading to an underestimation of the neutron attenuation effect in concrete.

\section{Acknowledgement}

The authors would like to thank Konstanze Gunzert-Marx and Dieter Schardt (GSI) for supplying the neutron spectra. 


\section{References}

[1] W.F. Henning, Plans for the future facility at GSI, in: J.M. D'Auria, J. Thomson, M. Comyn (Ed.), Proceedings of the $14^{\text {th }}$ conference on electromagnetic isotope separators and techniques related to their applications, Victoria, BC, Canada, 6-10 May 2002, Nucl. Instr. and Meth. B 204 (2003) 725.

[2] T. Motobayashi, RI beam factory project at RIKEN, in: J.M. D'Auria, J. Thomson, M. Comyn (Ed.), Proceedings of the $14^{\text {th }}$ conference on electromagnetic isotope separators and techniques related to their applications, Victoria, BC, Canada, 6-10 May 2002, Nucl. Instr. and Meth. B 204 (2003) 736.

[3] B.M. Sherill, Overview of the Rare Isotope Accelerator project, in: J.M. D'Auria, J. Thomson, M. Comyn (Ed.), Proceedings of the $14^{\text {th }}$ conference on electromagnetic isotope separators and techniques related to their applications, Victoria, BC, Canada, 6-10 May 2002, Nucl. Instr. and Meth. B 204 (2003) 765.

[4] G. Savard, Status of the $R \& D$ for the rare isotope accelerator project, in: J.M. D'Auria, J. Thomson, M. Comyn (Ed.), Proceedings of the $14^{\text {th }}$ conference on electromagnetic isotope separators and techniques related to their applications, Victoria, BC, Canada, 6-10 May 2002, Nucl. Instr. and Meth. B 204 (2003) 771.

[5] A. Fassò, A. Ferrari and P.R. Sala, Electron-photon transport in FLUKA: status, in: A. Kling, F. Barao, M. Nakagawa, L. Tavora, P. Vaz (Eds.), Proceedings of the Monte Carlo 2000 Conference, Lisbon, 23-26 October 2000, Springer-Verlag Berlin (2001) p. 159.

[6] A. Fassò, A. Ferrari, J. Ranft and P.R. Sala, FLUKA: status and prospective for hadronic applications, in: A. Kling, F. Barao, M. Nakagawa, L. Tavora, P. Vaz (Eds.), Proceedings of the Monte Carlo 2000 Conference, Lisbon, 2326 October 2000, Springer-Verlag Berlin (2001) p. 955.

[7] R.E. Prael and H. Lichtenstein, User guide to LCS: The LAHET Code System, LA-UR-89-3014, Los Alamos National Laboratory, Los Alamos, New Mexico (1989).

[8] N.V. Mokhov, S.I. Striganov, A. Van Ginneken, S.G. Mashnik, A.J. Sierk and J. Ranft, MARS code developments, in: T. Gabriel (Ed.), Proceedings of the Fourth Workshop on Simulating Accelerator Radiation Environments (SARE4), Knoxville (TN, USA), 14-16 September 1998, ORNL (1998) p. 87.

[9] V. Andersen et al., The FLUKA code for space applications: recent developments, Proceedings of the $34^{\text {th }}$ COSPAR scientific assembly, World Space Congress, Houston, Texas, USA, 10-19 October 2002, Advances in Space Research (in press).

[10] H. Iwase, T. Kurosawa, T. Nakamura, N. Yoshizawa and J. Funabiki, Development of heavy ion transport Monte Carlo code, Nucl. Instr. and Meth. B 183 (2001) 374.

[11] H. Iwase, K. Niita and T. Nakamura, Development of general-purpose particle and heavy ion transport code, J. of Nucl. Sci. and Tech. 39 (2002) 1142.

[12] H. Iwase, Development and experimental evaluation of a general-purpose heavy-ion transport Monte Carlo code, Ph. D. Thesis, Tohoku University, March 2003. 
[13] B.J. Moyer, Evaluation of shielding required for the improved Bevatron, Lawrence Radiation Laboratory Report UCRL-9769, June 1961 and B.J. Moyer, Method of Calculating the Shielding Enclosure of the Bevatron, in: Premier Colloque International sur la Protection Auprés des Grands Accélérateurs (Presses Universitaires de France, Paris, 1962).

[14] T. Kurosawa, N. Nakao, T. Nakamura, Y. Uwamino, T. Shibata, N. Nakanishi, A. Fukumura and K. Murakami, Measurements of secondary neutrons produced from thick targets bombarded by high-energy helium and carbon ions, Nucl. Sci. and Eng. 132 (1999) 30.

[15] T. Kurosawa, N. Nakao, T. Nakamura, Y. Uwamino, T. Shibata, A. Fukumura and K. Murakami, Measurements of secondary neutrons produced from thick targets bombarded by high energy neon ions, J. of Nucl. Sci. and Tech. 36 (1999) 41.

[16] T. Kurosawa, N. Nakao, T. Nakamura, H. Iwase, H. Sato, Y. Uwamino and A. Fukumura, Neutron yields from thick $\mathrm{C}, \mathrm{Al}, \mathrm{Cu}$ and $\mathrm{Pb}$ targets bombarded by $400 \mathrm{MeV} / n u c l e o n \mathrm{Ar}, \mathrm{Fe}$, Xe and $800 \mathrm{MeV} / n u c l e o n$ Si ions, Phys. Rev. C 62, Third series, No. 4 (2000).

[17] S. Agosteo, T. Nakamura, M. Silari and Z. Zajacova, Attenuation curves in concrete of neutrons from 100-400 MeV per nucleon $\mathrm{He}, \mathrm{C}, \mathrm{Ne}, \mathrm{Ar}, \mathrm{Fe}$ and Xe ions on various targets, Nucl. Instrum. Meth. B 217 (2004) 221.

[18] K. Gunzert-Marx, Nachweis leichter Fragmente aus Schwerionenreaktionen mit einem BaF-Teleskop-Detektor (Messungen im Rahmen des Tumortherapieprojekts der GSI), PHD-work (in German), Technical University Darmstadt, January 2004.

[19] C. Scheidenberger and H. Geissel, Penetration of relativistic heavy ions through matter, Nucl. Instr. and Meth. B 135 (1998) 25.

[20] H. Geissel and C. Scheidenberger, Slowing down of relativistic heavy ions and new applications, Nucl. Instr. and Meth. B 136-138 (1998) 114.

[12] National Council of Radiation Protection, Radiation protection design guidelines for 0.1-100 MeV particle accelerators facilities, NCRP Report 51 (1977).

[22] R.C. McCall, T.M. Jenkins and R.A. Shore, Transport of accelerator produced neutrons in a concrete room, IEEE Trans. Nucl. Sci. NS-26 (1979) 1593.

[23] A. Ferrari and P.R. Sala, The physics of high energy reactions, in: A. Gandini and G. Reffo (Eds.), Proceedings of the Workshop on Nuclear Reaction Data and Nuclear Reactor Physics, Design and Safety, International Centre for Theoretical Physics, Miramare-Trieste (Italy), 15 April-17 May 1996, Vol. 2, World Scientific (1998) p. 424.

[24] A. Ferrari and M. Pelliccioni, Fluence to dose equivalent conversion data and effective quality factors for high energy neutrons, Radiat. Prot. Dosim. 76 (1998) 215.

[25] M. Pelliccioni, Overview of fluence-to-effective dose and fluence to-ambient dose equivalent conversion coefficients for high-energy radiation calculated using the FLUKA code, Radiat. Prot. Dosim. 88 (2000) 279.

[26] R.H. Thomas and G.R. Stevenson, Radiological safety aspects of the operation of proton accelerators, IAEA Technical Reports Series No. 283, Vienna (1988). 
[27] H.-P. Weise, Shielding of high energy heavy ion accelerators, Proceedings of the $7^{\text {th }}$ International Conference on Radiation Shielding, Bournemouth (UK), 12-16 September 1988, Vol. 3 (1988) p. 903.

[28] Gutachten der BAM (Bundesanstalt für Materialforschung) zur "Abschirmung des geplanten Schwerionen-Synchrotrons der Gesellschaft für Schwerionenforschung (GSI)"; 11.06.1986 (in German); unpublished.

[29] D. Filges and G. Sterzenbach, Ergebnisbericht für erste theoretische Untersuchungen zur Erzeugung von Neutronenflußspektren mit Protonen und Ionen an einem Eisentarget für Abschirmuntersuchungen am geplanten GSISpeicherring, Institut für Reaktorentwicklung, KFA Jülich, Aktennotiz 02/1986 (in German), unpublished.

[30] M.-C. Lemaire, S. Nagamiya, O. Chamberlain, G. Shapiro, S. Schnetzer, H. Steiner and I. Tanihata, Tables of light-fragment inclusive cross sections in relativistic heavy ion collisions, LBL-Report 8463, Lawrence Berkeley Laboratory (1979).

[31] S. Agosteo, C. Birattari, A. Foglio Para, M. Silari and L. Ulrici, Neutron measurements around a beam dump bombarded by high energy protons and lead ions, Nucl. Instr. and Meth. A 459 (2001) 58.

[32] S. Agosteo, C. Birattari, A. Foglio Para, A. Mitaroff, M. Silari and L. Ulrici, $90^{\circ}$ neutron emission from high energy protons and lead ions on a thin lead target, Nucl. Instr. and Meth. A 476 (2002) 63.

[33] S. Agosteo, C. Birattari, A. Foglio Para, L. Gini, A. Mitaroff, M. Silari and L. Ulrici, Neutron production from $158 \mathrm{GeV} / \mathrm{c}$ per nucleon lead ions on thin copper and lead targets in the angular range $30^{\circ}-135^{\circ}$, Nucl. Instr. and Meth. B 194 (2002) 399.

[34] S. Agosteo, C. Birattari, A. Foglio Para, E. Nava, M. Silari and L. Ulrici, Neutron measurements in the stray field produced by $158 \mathrm{GeV} / \mathrm{c}$ lead ion beams, Health Phys. 75 (1998) 619.

[35] T. Nunomiya, S. Yonai, M. Takada, A. Fukumura and T. Nakamura, Shielding experiment of heavy-ion produced neutrons using a tissue-equivalent proportional counter, Radiat. Prot. Dosim. 106 (2003) 207. 